\title{
Penambahan Tepung Cangkang Udang dalam Pakan Buatan Sebagai Penguat Warna Ikan Koi (Cyprinus carpio L.)
}

Additioning of Shrimp's Carapace's Flour in Artificial Food as Color enhancer of Koi (Cyprinus carpio L.)

\author{
Arry Yusnita Saloh ${ }^{1}$, Yuniarti Aida ${ }^{1^{*}}$, Felicia Zahida ${ }^{1}$ \\ Fakultas Biologi, Universitas Atma Jaya Yogyakarta *Penulis untuk korespondensi \\ E-mail: yuni@ygy.centrin.net.id
}

\begin{abstract}
Shrimp's skin and carapace has been used as color enhancement. The shrimp's skin and carapace was pounded into flour and added to the commercial pellet available locally. The shrimp's flours contains red pigmen astaxanthine. The Koi's used in this experiment were two months old Cyprinus carpio $L$ var kohaku. Five level of different concentration of shrimp's flour were used i.e. $5.7 \%, 8.5 \%, 11.4 \%, 14.2 \%$, and $17.1 \%$ respectively. Each aquarium contains three fishes were used in threeplicate and reared for 8 weeks. Five main color or hue was observed i.e. Redish Orange, Pastel Orange, Orange Red or Yellowish Red, Red and High Red or Vivid Red. 15 panelis have been used to give their comments to the color enhancement. The results shows that the value of the fish's color didn't change much, but the chrome intensity increase on week eight. Statistical analysis of Kruskall-Wallis and Mann-Whitney Test shows that on the concentration of shrimp flour of $11,4 \%$ was giving the best value for hue and chrome. On the consentration of $14,2 \%$ and $17,1 \%$ the results were not strong enough. This is probably because the concentration of the flour reaches maximum at $11,4 \%$ and giving maksimum color enhancement level so that more additioing didn't gave any change.
\end{abstract}

Key Words: Astaxantine, color enhancement, Cyprinus carpio L var kohaku, KruskallWallis Test, and Mann-Whitney Test.

Diterima: 16 Agustus 2004, disetujui: 25 Oktober 2004

\section{Pendahuluan}

Koi merupakan ikan hias favorit dan banyak digemari masyarakat luas, karena warna tubuhnya yang indah. Saat ini menjadi salah satu komoditas perdagangan yang cukup baik dalam bidang perikanan. Berbeda dengan ikan konsumsi, ikan hias mempunyai keunikan tersendiri. Apabila ikan konsumsi nilai atau harganya ditentukan oleh berat dan rasanya, nilai ikan hias ditentukan dari penampilannya. Warna yang cemerlang, bentuk yang indah, sehat dan lincah merupakan daya tarik ikan hias bagi penggemarnya. Berkaitan dengan keindahan warna Koi, untuk mempertahankan dan mencemerlangkan warna tubuhnya, diperlukan modifikasi melalui pakan. Pakan selain gizinya memenuhi, harus mudah dicerna dan diserap oleh tubuh serta mengandung pigmen merah, orange dan kuning yang dapat dibuat sendiri atau diperoleh di toko-toko ikan.

Kendati secara genetis pigmen warna sudah cukup baik, selama hidupnya ada kemungkinan mengalami perubahan, karena berbagai faktor lingkungan, misalnya sinar matahari. Oleh karena itu, perlu penambahan pigmen lewat pakan untuk memperbaiki keseimbangan warna Koi (Tiana dan Murhananto, 2002). Warna merah, orange dan kuning merupakan warna yang mendominasi ikan hias air tawar. Komponen utama atau bahan pembentuk sel pigmen merah, orange 
dan kuning adalah karoten yang diambil dari pakan. Ikan Koi tidak dapat mensintesis karoten sendiri, tetapi dapat menyimpannya, kecuali sel pigmen melanin dan pigmen guamin Koi dapat mensintesis dan menyimpannya. Oleh karena itu, zat karoten harus ada dalam pakan (Bachtiar dan Tim Lentera, 2002 ; Lesmana, 2002).

Ada 600 jenis karoten yang telah diketahui dan dapat diisolasi, baik dari tumbuhan maupun hewan. Karoten yang berasal dari wortel (tumbuhan) hanya mengandung satu macam karoten saja yaitu beta-karoten yang berwarna orange (Lesmana, 2002). Sumber karoten lain berupa astaxanthin berasal dari udang (hewan). Cangkang udang merupakan pakan ikan dengan kandungan astaxanthin yang sangat tinggi, karena hewan ini dapat mensintesis dan menyimpan astaxanthin cukup efektif (Lesmana, 2002). Mengingat Koi digemari masyarakat, sangat menarik dilakukan penelitian mengenai pengaruh cangkang udang terhadap kecerahan warna Koi. Selain itu cangkang udang ini mudah diperoleh dan diolah, harga yang relatif murah, bukan bahan makanan pokok manusia serta hasil limbah industri dan rumah tangga yang dapat dimanfaatkan. Diharapkan warna ikan menjadi lebih terang, sehingga mampu mempertahankan kualitas ikan Koi sebagai ikan hias.

\section{Metode Penelitian}

\section{Waktu dan Lokasi Penelitian}

Penelitian dilaksanakan selama 3 bulan, yaitu bulan Oktober sampai Desember 2003 di Laboratorium Tugas Akhir Fakultas Biologi Universitas Atma Jaya Yogyakarta.

\section{Bahan dan Alat}

Ikan Koi varietas kohaku berusia 2 bulan dengan panjang tubuh $5-8 \mathrm{~cm}$, cangkang udang air laut, diperoleh dari limbah pabrik pembekuan udang dan rumah makan- rumah makan. Pakan buatan floating type buatan PT Central Proteinaorima Indonesia. Bahan kimia yang digunakan untuk analisis kualitas air berupa larutan $\mathrm{MnSO} 4, \mathrm{KOH}-\mathrm{Kl}, \mathrm{H} 2 \mathrm{SO} 4$ (p),
$\mathrm{Na} 2 \mathrm{~S} 2 \mathrm{O} 3, \quad \mathrm{NaOH} \quad 0.02 \mathrm{~N}$, amilum dan indikator pp (phenolptalin).

Untuk warna sampel, digunakan kamus warna Methuen handbook of Colour (Kornerup and Wanscher, 1978). Alat-alat yang akan digunakan selama penelitian adalah : akuarium kecil berukuran $30 \times 20 \times 20 \mathrm{~cm}$ untuk media hidup Koi, aerator, alat penyaring atau filter air, penggiling tepung, alat pencetak pakan ikan, ayakan tepung, timbangan digital mikro analitik Ohaus. Alat untuk menganalisis kualitas air berupa thermometer batang, $\mathrm{pH}$ meter, erlenmeyer $100 \mathrm{ml}$, mikroburet syrink dan pipet.

\section{Tahap Persiapan}

Disiapkan 18 akuarium yang berukuran $30 \mathrm{~cm} \times 20 \mathrm{~cm} \times 20 \mathrm{~cm}$ yang masing-masing akuarium diisi air setinggi $15 \mathrm{~cm}$ serta pemberian aerasi untuk meningkatkan kandungan oksigen dalam air. Disediakan bibit ikan Koi (Cyprinus carpio L.) yang berumur 23 bulan dengan panjang 5-8 $\mathrm{cm}$. Aklimasi ikan dilakukan selama \pm 7 hari. Bibit ikan diperoleh dari Mina Karya Koi Centre Berbah, Sleman, Yogyakarta.

\section{Pembuatan Pakan Uji}

Pakan pabrik berupa pelet yang masih berbentuk butiran digerus dengan penggiling sehingga berbentuk remah yang lebih halus, kemudian mencampurkan bahan tepung cangkang udang yang persentase terkecil, dilanjutkan bahan persentase terbesar.

\section{Tahap Pemeliharaan dan Perlakuan}

Kombinasi perlakuan pada pakan buatan dapat dilihat pada Tabel 1. Pakan buatan diberikan dalam bentuk remah.

Ditebarkan benih ikan masing-masing akuarium 3 ekor. Diberi pakan sebanyak $10 \%$ per hari dengan berat badan $\pm 3-10 \mathrm{~g}$ dengan frekuensi pemberian pakan 2 kali sehari pagi dan sore ( \pm jam 09.00 dan 16.00 wib) (Effendy, 1993 ; Tiana dan Murhananto, 2002).

\section{Pengukuran Kualitas Air}

Pengukuran temperatur air akuarium dilakukan dengan menggunakan termometer 
batang pada skala ${ }^{\circ} \mathrm{C}$. Pengukuran $\mathrm{pH}$ dilakukan dengan menggunakan $\mathrm{pH}$ meter yang dicelupkan ke dalam akuarium penelitian.

Pengukuran Kadar Oksigen Terlarut (DO) dan $\mathrm{CO}_{2}$ bebas dilakukan dengan menggunakan Metode Mikro-Winkler.

\section{Cara Analisis Warna Sampel}

Warna ikan Koi yang akan diamati meliputi 3 dimensi warna yang terdapat pada

Tabel 1. Kombinasi Pakan Buatan Berupa Pelet dan Cangkang Udang

\begin{tabular}{cccc}
\hline \hline Perlakuan & Pelet (\%) & Tepung Cangkang Udang (\%) & Astaxanthin (\%) \\
\hline \hline Kontrol & 100 & - & - \\
A & 94,3 & 5,7 & 0,5 \\
B & 91,5 & 8,5 & 0,75 \\
C & 88,6 & 11,4 & 1 \\
D & 85,8 & 14,2 & 1,25 \\
E & 82,9 & 17,1 & 1,5 \\
\hline \hline
\end{tabular}

\section{Hasil Dan Pembahasan}

Minggu ke-0 merupakan awal penelitian, warna ikan koi belum mengalami perubahan, sehingga warna awal yang diamati oleh panelis adalah Redish Orange, dengan skala warna 7A6, 7A7, 7A8, 7B7 dan 7B8. (Tabel 2). Minggu ke-4 menunjukkan peningkatan hasil warna ikan Koi secara drastis. Pengamatan warna Koi pada minggu ini menghasilkan dua warna baru Red dan High Red $=$ Vivid Red . Warna Orange Red $=$ Yellowish Red masih dijumpai sampai akhir penelitian yaitu minggu ke-8 (Tabel 3). Meningkatnya warna ke High Red=Vivid Red menunjukkan warna Koi merah cemerlang berarti sel pigmen bertambah banyak. Peningkatan warna Red mulai terlihat pada perlakuan A (penambahan tepung cangkang udang 5,7 \% yang mengandung astaxanthin $0,5 \%$ ) memperoleh angka tertinggi, sedangkan warna High Red=Vivid Red terlihat peningkatannya pada perlakuan $\mathrm{C}$ (penambahan tepung cangkang udang 11,4\% yang mengandung astaxanthin 1 $\%)$ memperoleh angka tertinggi daripada perlakuan lain. Minggu ke-6 sampai minggu ke-8 warna High Red=Vivid Red angkanya terus meningkat pada perlakuan $\mathrm{C}$ dengan nilai value sangat terang dan nilai chroma tertingi. Artinya penambahan tepung cangkang udang skala warna. Ketiga komponen warna ini tercantum dalam buku Kamus Warna Methuen Handbook of Colour (Kornerup and Wanscher, 1978). Hasil penelitian responden kemudian dianalisis secara deskriptif dan statistik dengan Uji Kruskall - Wallis dan dilanjutkan dengan Uji Mann - Whitney untuk mengetahui perbedaan antar perlakuan (Sudjana, 1996).

11,4 persen pada perlakuan $\mathrm{C}$ adalah yang terbaik daripada perlakuan yang lain, sebab pigmen astaxanthin dalam cangkang udang mampu meningkatkan jumlah sel pigmen Xantofor ikan Koi, sehingga diperoleh warna High Red=Vivid Red (warna terbaik) untuk jenis ikan Koi varietas Kohaku. Sebaliknya jika kepadatan sel-sel pigmen berkurang, warna Koi semakin memudar. Pigmen yang berada tepat di bawah sisik membuat warna Koi tampak bagus, sedangkan pigmen yang letaknya di bagian tengah dan di bagian bawah lapisan koloid menyebabkan warna $h i$ (merah) tidak baik dan kualitas Koi buruk. Namun, keberadaan pigmen tersebut dapat diperoleh dengan pemberian bahan-bahan tertentu pada pakannya untuk memperbaiki warna Koi. Astaxanthin yang terkandung dalam tepung cangkang udang secara umum langsung diserap dan digunakan oleh ikan Koi sebagai sel pigmen merah (Lesmana, 2002).

Namun, tidak diketahui secara pasti bagaimana penyerapan dan penyimpanan astaxanthin di dalam tubuh ikan. Menurut Sediaoetama (1987), penyerapan pro-vitamin A terutama dilakukan di bagian proksimal dari usus halus. Setelah melintasi usus, pro-vitamin A bersama lemak diserap masuk ke limfa kemudian masuk ke dalam aliran darah dan jaringan tubuh lainnya termasuk sel pigmen, 
sehingga warna tubuh ikan menjadi lebih terang. Adanya gangguan lemak akan menimbulkan gangguan penyerapan vitamin A dan vitamin lainnya yang larut dalam lemak. Astaxanthin terkenal sebagai bahan provitamin A. Pro-vitamin A adalah zat organik yang tidak mempunyai kegiatan biologis vitamin, tetapi setelah dikonsumsi oleh tubuh

Tabel 2. Hasil Pengamatan Warna Ikan Koi oleh Panelis

Warna Ikan Pada Awal Penelitian (Minggu ke-0)

\begin{tabular}{|c|c|c|}
\hline \multicolumn{3}{|c|}{ Warna Ikan Pada Awal Penelitian (Minggu ke-0) } \\
\hline Perlakuan & Skala Warna & Warna \\
\hline \multirow{3}{*}{ Kontrol } & $\begin{array}{l}7 \mathrm{~A} 6=17 \\
7 \mathrm{~A} 7=39 \\
7 \mathrm{~A} 8=12\end{array}$ & Redish Orange \\
\hline & $\begin{array}{l}7 \mathrm{~A} 5=12 \\
8 \mathrm{~A} 5=3\end{array}$ & Pastel Red \\
\hline & $\begin{array}{l}8 \mathrm{~A} 6=3 \\
8 \mathrm{~A} 7=12 \\
8 \mathrm{~A} 8=37\end{array}$ & Orange Red $=$ Yellowish Red \\
\hline \multirow{3}{*}{$\mathbf{A}$} & $\begin{array}{l}7 \mathrm{~A} 6=24 \\
7 \mathrm{~A} 7=15 \\
7 \mathrm{~A} 8=6\end{array}$ & Redish Orange \\
\hline & $\begin{array}{l}7 \mathrm{~A} 4=9 \\
7 \mathrm{~A} 5=6 \\
8 \mathrm{~A} 4=12 \\
8 \mathrm{~A} 9=30 \\
9 \mathrm{~A} 5=3\end{array}$ & Pastel Red \\
\hline & $\begin{array}{l}8 \mathrm{~A} 6=3 \\
8 \mathrm{~A} 7=6 \\
8 \mathrm{~A} 8=21\end{array}$ & Orange Red $=$ Yellowish Red \\
\hline \multirow{2}{*}{$\mathbf{B}$} & $\begin{array}{l}7 \mathrm{~A} 6=27 \\
7 \mathrm{~A} 7=30 \\
7 \mathrm{~A} 8=6\end{array}$ & Redish Orange \\
\hline & $\begin{array}{l}7 \mathrm{~A} 4=9 \\
7 \mathrm{~A} 5=24 \\
8 \mathrm{~A} 5=36 \\
10 \mathrm{~A} 4=3\end{array}$ & Pastel Red \\
\hline \multirow[b]{2}{*}{$\mathbf{C}$} & $\begin{array}{l}7 \mathrm{~A} 6=42 \\
7 \mathrm{~A} 7=9 \\
7 \mathrm{~A} 8=6 \\
7 \mathrm{~B} 7=3\end{array}$ & Redish Orange \\
\hline & $\begin{array}{l}7 \mathrm{~A} 4=9 \\
7 \mathrm{~A} 5=24 \\
8 \mathrm{~A} 5=36 \\
10 \mathrm{~A} 4=3\end{array}$ & Pastel Red \\
\hline \multirow[t]{2}{*}{ D } & $\begin{array}{l}7 \mathrm{~A} 6=45 \\
7 \mathrm{~A} 7=36 \\
7 \mathrm{~A} 8=6 \\
7 \mathrm{~B} 7=3 \\
7 \mathrm{~B} 8=3\end{array}$ & Redish Orange \\
\hline & $\begin{array}{l}7 \mathrm{~A} 4=3 \\
7 \mathrm{~A} 5=9 \\
8 \mathrm{~A} 4=27 \\
9 \mathrm{~A} 4=3\end{array}$ & Pastel Red \\
\hline \multirow{2}{*}{$\mathbf{E}$} & $\begin{array}{l}7 \mathrm{~A} 6=12 \\
7 \mathrm{~A} 7=48 \\
7 \mathrm{~A} 8=12\end{array}$ & Redish Orange \\
\hline & $\begin{array}{l}7 \mathrm{~A} 4=6 \\
7 \mathrm{~A} 5=15 \\
8 \mathrm{~A} 4=3\end{array}$ & Pastel Red \\
\hline
\end{tabular}

hewan dan manusia diubah menjadi vitamin A. Jadi, $\beta$-karoten dan karoten lainnya merupakan bentuk pro-vitamin A. Pro-vitamin A terdapat pada tumbuhan, sedangkan vitamin A terdapat pada hewan (Lesmana, 2002 ; Sediaoetama, 1987). 
Tabel 3: Warna Ikan Pada Minggu ke-8 Penelitian

\begin{tabular}{|c|c|c|}
\hline Perlakuan & Skala Warna & Warna \\
\hline Kontrol & $\begin{array}{l}8 \mathrm{~A} 6=16 \\
8 \mathrm{~A} 7=25 \\
8 \mathrm{~A} 8=95\end{array}$ & Orange Red $=$ Yellowish Red \\
\hline \multirow{3}{*}{$\mathbf{A}$} & $\begin{array}{l}8 \mathrm{~A} 6=13 \\
8 \mathrm{~A} 7=3 \\
8 \mathrm{~A} 8=24\end{array}$ & Orange Red $=$ Yellowish Red \\
\hline & $\begin{array}{l}9 \mathrm{~A} 6=71 \\
9 \mathrm{~A} 7=17\end{array}$ & Red \\
\hline & $9 \mathrm{~A} 8=6$ & High Red $=$ Vivid Red \\
\hline \multirow{3}{*}{$\mathbf{B}$} & $\begin{array}{l}8 \mathrm{~A} 6=22 \\
8 \mathrm{~A} 7=22 \\
8 \mathrm{~A} 8=11\end{array}$ & Orange Red $=$ Yellowish Red \\
\hline & $\begin{array}{l}9 \mathrm{~A} 6=37 \\
9 \mathrm{~A} 7=16 \\
10 \mathrm{~A} 6=20 \\
10 \mathrm{~A} 7=1\end{array}$ & Red \\
\hline & $9 \mathrm{~A} 8=6$ & High Red = Vivid Red \\
\hline \multirow{3}{*}{$\mathbf{C}$} & $8 \mathrm{~A} 8=6$ & Orange Red $=$ Yellowish Red \\
\hline & $\begin{array}{l}9 \mathrm{~A} 6=4 \\
9 \mathrm{~A} 7=23 \\
10 \mathrm{~A} 7=9\end{array}$ & 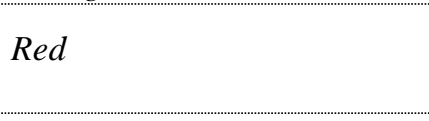 \\
\hline & $\begin{array}{l}9 \mathrm{~A} 8=76 \\
10 \mathrm{~A} 8=17\end{array}$ & High Red = Vivid Red \\
\hline \multirow{3}{*}{ D } & $8 \mathrm{~A} 8=7$ & Orange Red = Yellowish Red \\
\hline & $\begin{array}{l}9 A 6=24 \\
9 A 7=35 \\
10 A 6=3 \\
10 A 7=7\end{array}$ & Red \\
\hline & $\begin{array}{l}9 \mathrm{~A} 8=44 \\
10 \mathrm{~A} 8=15\end{array}$ & High Red $=$ Vivid Red \\
\hline \multirow{3}{*}{$\mathbf{E}$} & $8 \mathrm{~A} 8=17$ & Orange Red $=$ Yellowish Red \\
\hline & $\begin{array}{l}9 \mathrm{~A} 6=20 \\
9 \mathrm{~A} 7=21 \\
10 \mathrm{~A} 6=7 \\
10 \mathrm{~A} 7=6\end{array}$ & Red \\
\hline & $\begin{array}{l}9 \mathrm{~A} 8=57 \\
10 \mathrm{~A} 8=7\end{array}$ & High Red $=$ Vivid Red \\
\hline
\end{tabular}

Umumnya warna ikan adalah konstan atau tidak berubah dan spesifik untuk jenisnya. Perubahan warna biasanya terjadi hanya pada kecerahan dan keburamannya saja, disebabkan adanya perubahan jumlah sel pigmen (kromatofor) yang terdapat dalam dermis pada sisik, di luar maupun di bawah sisik. Tujuh puluh persen $(70 \%)$ kecerahan warna sangat dipengaruhi oleh faktor genetik ikan itu sendiri (Loka dan Roospitasari, 2002). Karakter atau sifat warna Koi ditentukan oleh genetik ikan dalam kromosom dan merupakan faktor yang diturunkan. Warna merupakan karakter kualitatif yang diperoleh dari sifat induk (jantan dan betina). Jika induk memiliki warna bagus dan cemerlang, keturunannya akan mewarisi warna yang sama (Bachtiar dan Tim Lentera, 2002). Warna-warna pada Koi sampai akhir penelitian diperoleh warna Orange Red=Yellowish Red, Red dan High Red=Vivid Red. Berarti secara genetis ikan Koi tersebut sudah membawa gen warna Orange Red=Yellowish Red, Red dan High Red=Vivid Red. Perlu untuk diketahui Koi yang digunakan untuk penelitian berupa benih usia 2-3 bulan pada awalnya berwarna samar-samar belum menampakkan warna yang sebenarnya hingga akhir penelitian terbentuk warna 
Orange Red=Yellowish Red, Red dan High Red=Vivid Red. Hasil perbandingan MannWhitney Test menunjukkan sangat beda nyata antara pakan buatan tanpa penambahan tepung cangkang udang dengan perlakuan yang diberi tepung cangkang udang seperti tertera pada Tabel 3.

Hasil Tabel 4 menunjukkan bahwa perlakuan A, B, C, D dan E memperlihatkan sangat beda nyata dengan perlakuan kontrol (tanpa pemberian tepung cangkang udang). Uji Mann-Whitney memperlihatkan juga perlakuan A (astaxanthin 0,5\%) berbeda nyata dengan perlakuan B (astaxanthin 0,75\%). Selanjutnya perlakuan C (astaxanthin $1 \%$ ), perlakuan D (astaxanthin 1,25 \%) dan perlakuan E (astaxanthin 1,5\%) sangat beda nyata dengan perlakuan A. Dari Mann-Whitney Test ini menunjukkan perlakuan $\mathrm{C}$ (astaxanthin $1 \%$ ) memiliki nilai chroma tertinggi dan sangat beda nyata dibandingkan perlakuan $\mathrm{A}, \mathrm{B}, \mathrm{D}$ dan E. Perlakuan B menunjukkan sangat beda nyata dengan perlakuan C, D dan E. Selain itu terdapat beda nyata antara perlakuan $\mathrm{C}$ terhadap perlakuan D dan perlakuan E. Begitu pula dengan perlakuan $\mathrm{D}$, diperoleh hasil adanya beda nyata dengan perlakuan E. Hasil pengujian statistik nonparametrik di atas memperlihatkan perlakuan A, B, C, D dan E cukup mampu meningkatkan hasil warna ikan Koi menjadi lebih cerah atau tajam. Namun perlakuan C (astaxanthin $1 \%$ ) menunjukkan hasil yang signifikan daripada konsentrasi yang lain dalam mempertajam warna Koi, sedangkan perlakuan E tidak menunjukkan perbedaan yang berarti. Jadi, pemberian tepung cangkang udang $11,4 \%$ yang mengandung pigmen astaxanthin $1 \%$ cukup untuk meningkatkan warna menjadi lebih terang dan cemerlang, khususnya ikan Koi berwarna merah putih (Kohaku). Demikian pula pemberian yang berlebihan merupakan pemborosan, karena warna maksimal yang sudah tercapai tidak akan lebih meningkat lagi. Artinya, astaxanthin diperlukan oleh ikan dalam jumlah seperlunya saja. Oleh karena itu, tidak berarti bahwa pemberian astaxanthin yang banyak akan menyebabkan warna ikan semakin merah. Warna ikan dibatasi oleh kemampuan dan kapasitas sel-sel pengatur warna pada ikan. Jadi, pemberian astaxanthin yang berlebihan secara alamiah akan dibuang oleh ikan berupa faeces. Dan untuk mempertahankan warna cemerlang, pakan buatan yang mengandung astaxanthin diberikan terus menerus (tetap) pada ikan hias (McCoy, 1999).

Tabel 4. Hasil Mann-Whitney Test pada Masing-Masing Perlakuan

\begin{tabular}{|c|c|c|c|c|c|c|}
\hline Perlakuan & Kontrol & A & $\mathrm{B}$ & $\mathrm{C}$ & $\mathrm{D}$ & $\mathrm{E}$ \\
\hline Kontrol & - & $* *$ & $* *$ & $* *$ & $* *$ & $* *$ \\
\hline A & $* *$ & - & $*$ & $* *$ & $* *$ & $* *$ \\
\hline B & $* *$ & * & - & $* *$ & $* *$ & $* *$ \\
\hline $\mathrm{C}$ & $* *$ & $* *$ & $* *$ & - & $*$ & * \\
\hline $\mathrm{D}$ & $* *$ & $* *$ & $* *$ & $*$ & - & * \\
\hline E & $* *$ & $* *$ & $* *$ & $*$ & $*$ & - \\
\hline \multicolumn{7}{|c|}{$\begin{aligned} \text { Keterangan : } & * \text { terdapat beda nyata } \\
* * & =\text { sangat beda nyata } \\
\text { Perlakuan kontrol } & =\text { Tanpa pemberian tepung cangkang udang } \\
\mathrm{A} & =\text { Pakan buatan dengan pemberian tepung cangkang udang } 5,7 \% \\
\mathrm{~B} & =\text { Pakan buatan dengan pemberian tepung cangkang udang } 8,5 \% \\
\mathrm{C} & =\text { Pakan buatan dengan pemberian tepung cangkang udang } 11,4 \% \\
\mathrm{D} & =\text { Pakan buatan dengan pemberian tepung cangkang udang } 14,2 \% \\
\mathrm{E} & =\text { Pakan buatan dengan pemberian tepung cangkang udang } 17,1 \%\end{aligned}$} \\
\hline
\end{tabular}




\section{Kualitas Air}

Suhu air selama penelitian berkisar antara $25-27^{\circ} \mathrm{C}$, (Tabel 5). Kisaran suhu ini sesuai dengan kebutuhan Koi untuk mempertahankan pertumbuhannya agar tetap normal. Suhu optimal yang diperlukan Koi sekitar $24-28^{\circ} \mathrm{C}$. suhu diatas $28^{\circ} \mathrm{C}$ menyebabkan nafsu makan Koi tinggi sehingga Koi menjadi cepat gemuk, akibatnya kulit Koi berkembang tetapi warna memudar, disebabkan jumlah sel pigmen Koi tidak bisa memenuhi luas permukaan yang didukungnya.

pH air selama penelitian 6,9-8,3 (Tabel 5), berada pada kisaran normal untuk Koi hidup sehat yaitu pada $6,5-8,5$.
Kisaran oksigen terlarut menunjukkan kisaran oksigen yang cukup sekitar 5,2-6,7 ppm (Tabel 5), berarti kadar oksigen terlarut dalam air akuarium terpenuhi.

Karbondiosida menunjukkan kisaran 10,3 - 17,5 ppm, tetapi $\mathrm{CO}_{2}$ terlarut. Minggu ke-4 rentangnya jauh dari yang lain, (Tabel 5). Hal ini disebabkan akibat banyaknya hasil ekskresi ikan dan pakan yang tersisa menyebabkan air menjadi cepat keruh serta akibat proses respirasi Koi. Namun kisaran ini diabaikan, karena kadar O2 terlarut dalam akuarium berada pada kondisi yang cukup bagi Koi.

Tabel 5. Hasil Kisaran Kualitas Air Selama Penelitian

\begin{tabular}{lccccc}
\hline \hline \multicolumn{1}{c}{ Parameter } & \multicolumn{5}{c}{ Minggu ke- } \\
& 0 & 2 & 4 & 6 & 8 \\
\hline \hline Suhu air $\left({ }^{\circ} \mathrm{c}\right)$ & $25-26$ & 26 & 26 & $26-27$ & $26-26,5$ \\
$\mathrm{pH}$ air & $7,0-7,1$ & $6,9-7,7$ & $6,9-7,5$ & $7,3-7,6$ & $7,4-8,3$ \\
$\mathrm{DO}(\mathrm{ppm})$ & $5,2-6,6$ & $5,9-6,5$ & $5,7-6,6$ & $5,8-6,7$ & $5,8-6,5$ \\
$\mathrm{CO}_{2}(\mathrm{ppm})$ & $13,7-14,7$ & $13,3-14,8$ & $10,3-17,5$ & $15-16,7$ & $14,3-15,8$ \\
\hline \hline
\end{tabular}

\section{Kesimpulan}

Pemberian tepung cangkang udang 11,4 $\%$ (astaxanthin $1 \%$ ) merupakan konsentrasi yang optimal dalam meningkatkan hasil warna Koi (Cyprinus carpio L.) terutama nilai hue dan chroma. Pemberian astaxanthin dalam tepung cangkang udang mulai terlihat peningkatan warna selama 2 minggu. Pemberian astaxanthin yang berlebihan merupakan pemborosan pakan, karena warna maksimal sudah diperoleh.

\section{Daftar Pustaka}

Bachtiar, Y., dan Tim Lentera. 2002. Mencemerlangkan Warna Koi. AgroMedia Pustaka. Jakarta.

Effendy, H. 1993. Mengenal Beberapa Jenis Koi (Karper Jepang - Nishikigoi). Penerbit Kanisius. Yogyakarta.

Kornerup, A. and Wanscher, J.H. 1978. Methuen Handbook of Colour. $3^{\text {rd }}$ edition. Michelin House. London.

Lesmana, D.S. 2002. Agar Ikan Hias Cemerlang. Penebar Swadaya. Jakarta.
Loka, G.L. dan Roospitasari, K. 2002. Menyiapkan Koi untuk Kontes. Penebar Swadaya. Jakarta.

McCoy, M. 1999. Astaxanthin Market A Hard One To Crack. Chem. \& Eng. News. Dalam http://www.O-

Fish.com/species/astaxanthin.php. Down Load 7 Februari 2004

Sediaoetama, A.J.S. 1987. Vitaminologi Bagi Umum dan Tenaga Profesi di Indonesia, Balai Pustaka, Jakarta.

Sudjana, M.A. 1996. Metode Statistika. Tarsito. Bandung.

Tiana, O.A., dan Murhananto. 2002. Budidaya Koi. Cetakan ke-1. AgroMedia Pustaka. Jakarta. 